\title{
AS LEMBRANÇAS SE CONSERVAM EM NOSSO CÉREBRO? UM PROBLEMA BERGSONIANO
}

\author{
DO MEMORIES REMAIN IN OUR BRAIN? A BERGSONIAN PROBLEM \\ ¿LOS RECUERDOS SE CONSERVAN EN NUESTRO CEREBRO? UN PROBLEMA \\ BERGSONIANO
}

Caio César Costa Santos

Universidade Federal de Sergipe - UFS

E-mail: cesarinmind@gmail.com

\section{RESUMO}

A temática central deste artigo reside na resposta à questão: as lembranças se conservam em nosso cérebro? De início, parece-nos uma questão de fácil resposta se respondêssemos categoricamente que as lembranças se alojam em uma parte específica de nosso cérebro, tanto é que estamos acostumados com esta definição. Contudo, não é esta bem a proposta deste presente estudo. Amparado principalmente nas pesquisas dos filósofos Bergson (2009, 2010, 2014) e Deleuze (2012), este estudo mostrará que as lembranças residem nelas mesmas, ou melhor, "na" duração. Entende-se por "duração" uma sucinta passagem ou uma mudança repentina da evolução do tempo. O nosso objetivo é demonstrar que a hipótese dos neurocientistas quanto à localização das lembranças está equivocada, pois, segundo a perspectiva bergsoniana, há uma coexistência modo-temporal entre o atual, a percepção e o virtual, a lembrança. Logo, o cérebro, enquanto matéria, não pode comportar essa tal coexistência.

PALAVRAS-CHAVE: Lembranças. Cérebro. Conservação.

\section{ABSTRACT}

The central theme of this article lies in the answer to the question: do memories remain in our brain? At first, it seems to us an easy question to answer if we categorically answered that memories are lodged in a specific part of our brain, so much so that we are accustomed with this definition. However, this is not the purpose of this present study. Supported mainly by the researches of the philosophers Bergson (2009, 2010, 2014) and Deleuze (2012), this study will show that the memories reside in themselves, or better, "in" the duration. "Duration" is understood as a succinct passage or a sudden change in the evolution of time. Our aim is to demonstrate that the neuroscientists' hypothesis regarding the location of memories is wrong, because, according to the Bergsonian perspective, there is a mode-temporal coexistence between the current, the perception and the virtual, the memory. Therefore, the brain, as matter, cannot support such coexistence.

KEYWORDS: Memories. Brain. Conservation.

\section{RESUMEN}

El tema central de este artículo radica en la respuesta a la pregunta: ¿los recuerdos se conservan en nuestro cerebro? Al principio, nos parece una pregunta fácil de responder si respondimos categóricamente que los recuerdos se encuentran en una parte específica de nuestro cerebro, tanto es así que estamos acostumbrados a esta definición. Sin embargo, este no es el propósito de este presente estudio. Apoyado principalmente por las investigaciones de los filósofos Bergson (2009, 2010, 2014) y Deleuze (2012), este estudio mostrará que los recuerdos residen en sí mismos, o mejor, "en" la duración. La "duración" se entiende como un pasaje sucinto o un cambio repentino en la evolución del tiempo. Nuestro objetivo es demostrar que la hipótesis de los neurocientistas con respecto a la ubicación de los recuerdos es errónea, porque, según la perspectiva bergsoniana, existe una coexistencia modo temporal entre la corriente, la percepción y lo virtual, la memoria. Por lo tanto, el cerebro, como materia, no puede soportar tal coexistencia.

PALABRAS-CLAVE: Recuerdos. Cerebro. Conservación. 


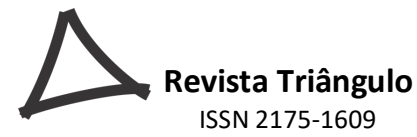

\section{INTRODUÇÃO}

Como o próprio título sugere, neste artigo, nós iremos tratar do seguinte problema: onde as lembranças se conservam? Será mesmo que existe um reservatório físico onde se alojam nossas lembranças? Qual a relação entre o nosso cérebro e as lembranças? Apresentaremos a visão de Bergson $(2009,2010,2014)$ o qual toma este problema filosófico e disseca um emaranhado de argumentos que aponta que as nossas lembranças existem por si mesmas, elas estão contidas "na" duração. O seu ponto de vista leva a crer que o nosso cérebro não é nada mais do que uma imagem em meio às outras tantas imagens que a virtualidade produz. Afirmaremos, com base na perspectiva bergsoniana, que o cérebro não possui a capacidade de armazenar nossas recordações uma vez que, quando tratamos de nossas memórias, há um complexo circuito coalescente de imagens que se imbricam entre si, formando uma relação coexistente entre o virtual e o real. Logo, nesta perspectiva, nosso cérebro não pode conter essa tal coexistência, ao contrário, o nosso cérebro funciona de modo atual, unicamente na instância do presente. Trataremos mais detidamente deste problema nas próximas seções.

\section{O CÉREBRO: APROXIMAÇÕES FILOSÓFICAS}

Muitos filósofos, desde Platão, argumentaram em torno do tema da memória, mas foram poucos, como Bergson, que elucidaram minuciosamente este problema filosófico, especificando detalhes do funcionamento, armazenamento e estocagem das lembranças na memória. Indo de encontro com os neurocientistas, os quais argumentam que as lembranças se alojam em uma parte específica de nosso cérebro, Bergson afirma categoricamente, dentro de um enquadre fenomenológico, que as lembranças existem nelas mesmas. Não há, pois, um reservatório, digamos, anatômico, que condense as nossas mais profundas recordações. Estas coexistem em si mesmas, embora seja preciso a presença do espírito para torná-las sensivelmente existentes no espaço e no tempo. Seguindo este princípio, fica um pouco difícil crer que as lembranças existem por si mesmas, mas o fato é que Bergson salienta que não há em qualquer extensão do espaço um "conteúdo" preciso que armazene as nossas lembranças por conta de seu estatuto ontológico.

Para o problema: onde as lembranças se conservam?, Deleuze (2012), importante estudioso de Bergson, vê um falso problema, isto é, um misto mal analisado. Segundo ele, 


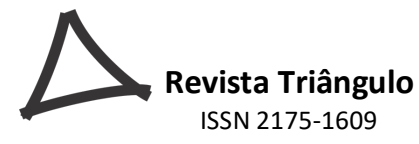

tomando como uma implicação este problema, "procede-se como se as lembranças tivessem de se conservar em alguma parte, como se o cérebro, por exemplo, fosse capaz de conservá-las. Mas, o cérebro está por inteiro na linha da objetividade.” (DELEUZE, 2012, p. 45). O que Deleuze quer nos dizer sobre a linha da objetividade? Que o nosso cérebro, por ele mesmo, é uma matéria, assim como qualquer outra entidade material existente na extensão do espaço. Não há porque dizer que o cérebro, enquanto uma matéria, conserve as nossas lembranças. Se disséssemos isto, seria uma falta de fundamento, uma ausência de perspectiva racional, um falso problema. O nosso cérebro se encontra na extensão do espaço como outro objeto qualquer físico e material e é impossível crer que ele seja um reservatório ou o substrato de nossas lembranças.

Ainda, segundo Deleuze (2012, p. 46, grifo do autor), “as lembranças só podem se conservar 'na' duração. Portanto, é em si que a lembrança se conserva". Vamos tomar o espaço como uma totalidade e os objetos nele contidos uma parte de sua extensão. O cérebro, portanto, só pode ser uma parte ou uma porção desta extensão. Já as nossas lembranças estão além desta extensão, jamais elas iriam "habitar" o espaço motor de interação entre corpos. Nesta perspectiva, o cérebro é um corpo dentro de um corpo maior. Se tratássemos o cérebro como um reservatório de lembranças, como tratam os neurocientistas, teríamos que conferir a um estado da matéria ou à matéria inteira este estado de conservação. E a matéria, enquanto força inerte no espaço, não pode ter o poder de conservar as lembranças que são ontologicamente e espiritualmente superiores à própria matéria.

As lembranças, contudo, se alojam "na" duração, no "decorrer" do tempo, na imediaticidade do momento atual, no seu devir. No instante em que o passado é, o passado foi. Ou seja, não há como interromper a força retrospectiva do passado, e se caso interrompêssemos nos tornaríamos loucos; sem uma visão recursiva do passado e sem identificação de si mesmo não saberíamos simplesmente quem somos. É uma falsa ilusão tomar o cérebro como reservatório de lembranças, pois é o mesmo que dizer que a nossa percepção é idêntica ao objeto percebido. Nós não percebemos os objetos do mundo tal como eles são, há, digamos, como que uma dissolução da imagem do objeto percebido. Nós vemos o objeto parecendo-nos como se aquele objeto fosse identicamente daquela maneira. $\mathrm{O}$ mesmo acontece com a diferença de natureza entre o cérebro e a lembrança, o atual e o virtual. $O$ cérebro é como se fosse uma primeira percepção, a matéria por excelência, enquanto que a lembrança é como se fosse metaforicamente uma névoa que se dissipa "na" duração. 


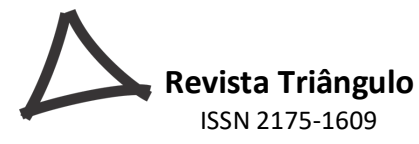

O objeto tal como nós o vemos se confunde com a percepção pura virtual, transformando o objeto percebido em uma espécime de “segunda ordem”. É a virtualidade do processo que faz ver uma coisa distinta daquela imersa no objeto percebido. À duração que coexiste no espaço e no tempo, trata-se de uma "passagem", de uma "mudança", de um "contínuo" que não cessam de acontecer. A duração ninguém vê, mas sente passar. A duração está na invisibilidade do objeto percebido, ou seja, no estado natural de mudança ou de ampliação deste objeto. Se todos os objetos que nos circundam se enquadram em uma linha de objetividade, a duração, pois, é a responsável por dar "movimento" às estruturas daqueles objetos. Eles, os objetos, avançam com a duração, quebram, desestruturam-se, envelhecem, perdem o brilho, etc. A duração é a que dá uma espécie de "afetividade" ao objeto inanimado. Não é um tipo de afetividade como a advinda da subjetividade humana, mas já se cerca de um movimento anímico que faz com que o objeto tome uma outra forma na extensão do espaço.

Mas, a característica de ver o objeto por uma segunda ordem, por um ponto de vista especial pertence à singularidade humana, em termos bergsonianos, à percepção pura virtual. O nosso olho tem a função de ver o objeto em sua relativa aparência, na condição de um movimento anímico meramente atual, mas são as lembranças subjacentes ao indivíduo que criam um novo sistema virtual de apreensão e de tomada de consciência do objeto percebido. Seguindo a perspectiva bergsoniana, se as nossas lembranças não estão no cérebro e sim na duração, então, fica claro para nós dizer que a lembrança junto à duração dá o contorno existencial àquele objeto, ou muito mais que isto, esta relação concerne o complexo itinerário de conjunção entre o dualismo atual/virtual. Tomando como exemplo o nosso cérebro, como dizemos anteriormente, ele não é mais do que um corpo, uma superfície que se insere e prolonga-se unicamente na atualidade. Dito de outra maneira, o cérebro funciona unicamente no presente, ele visa o contorno e as diretrizes de nosso corpo na instância atual. Como matéria, o cérebro não possui virtualidade, a condição de ser virtual pertence e está na inscrição do fundamento humano.

Só o homem é capaz de perceber virtualmente o objeto. Mas, aí o leitor poderia se questionar: mas o cérebro não faz parte do homem? Digamos que sim, mas o problema está em dizer que o cérebro, por ele mesmo, não faz nada a não ser se fixar e se prolongar na extensão do espaço. Junto à duração, ele é apenas uma matéria que se repete e que não se diferencia. A questão está na importância de se levar em consideração o virtual, ou seja, a consequente sobrevivência do passado em nossas vidas. Para deixar um pouco mais claro, o nosso cérebro 


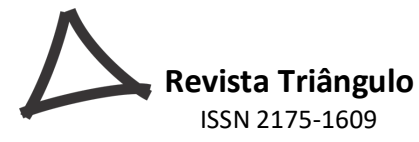

é, na verdade, um dado imediato diferentemente da imagem virtual encarnada em nossas lembranças. Toda a energia psíquica do conjunto de nossas lembranças se conserva nela mesma, o mesmo se pode dizer do inconsciente; não há, pois, "espaço" na extensão do mundo que "abrigue" ou que faça-nos localizar um determinado lugar para o inconsciente, bem como para a energia psíquica contida em uma porção de lembranças.

Segundo Deleuze (2012, p. 48), "assim como não percebemos as coisas em nós mesmos, mas ali onde elas estão, só apreendemos o passado ali onde ele está, em si mesmo, não em nós, em nosso presente". Estamos nos tratando de um passado eterno, de uma substância, se pudermos falar assim, de um elemento ontológico, universal. Trata-se, pois, de uma memória ontológica, ou seja, de um estado virtual que pertence à ontogenia do Ser. Não "ser humano", mas ser no sentido do verbo infinitivo "ser": a de ser alguma coisa, de pertencer a uma realidade extramaterial, extracorpórea, única e indissociável. Sem dúvida, as coisas exteriores mudam, mas seus momentos só se sucedem para uma consciência que os rememore. Sendo assim, as coisas só se sucedem e tomam forma a partir do virtual, da constelação de nossas lembranças, das profundezas de nosso ser. E estas profundezas não estão em um lugar específico, ao contrário, elas se movimentam no decorrer da duração.

Todavia, a duração, ela em si mesma, não muda a realidade virtual do objeto percebido a não ser com a presença de nossa consciência. Seguindo este mesmo raciocínio, a nossa consciência também tem um fundamento de ordem ontológica, ela não está contida em um reservatório específico material, ao contrário, ela está na intersecção entre o atual e o virtual, ou seja, entre a duração e a lembrança. Não existe consciência sem a lembrança. A própria consciência é já lembrança. A consciência está ou se encontra nas coisas da natureza. O mesmo podemos dizer do espaço. Nós não vemos o espaço, mas ele se encontra no arranjo das coisas que cerceiam o nosso universo perceptivo. Em contrapartida, o espaço é independente da nossa consciência, ele existe ipso facto. Porém, a estrita relação do objeto com o espaço é remodelada de acordo com a abrangência de nossa consciência, ou melhor, de nossa subjetividade.

A nossa subjetividade só pode ser compreendida pelos outros, porque nós podemos trocar sentimentos, sensações, percepções. Ou seja, aquele objeto que eu agora vejo certamente não será o mesmo quando eu retornar a vê-lo. Isto acontece porque a nossa consciência capta, absorve, significa, contextualiza, reflete, aprimora e é na prática destas ações que o objeto percebido nunca mais será o mesmo. Temos até a ilusão de que o objeto não se modificou, que ele continua o mesmo no espaço e no tempo, mas, no fim, na própria percepção inicial com o 


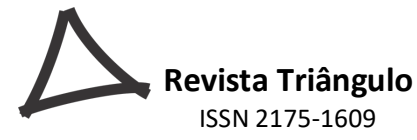

objeto, a mudança na duração já se consolida e a visão do mesmo objeto se complexifica ainda mais quando há uma interferência, mesmo que instantânea, da memória virtual. A tese central do pensamento de Bergson é a de que nós não percebemos somente os objetos atualmente, no presente única e exclusivamente, mas nós percebemos os objetos virtualmente.

O objeto dissocia-se porque eu insiro nele uma existência virtual. Esta existência virtual condensa as lembranças que eu mesmo recuperei das sucessivas vezes do meu contato ou da minha experiência com aquele dado objeto. Em poucas palavras, o objeto muda porque eu mudei. A percepção nunca mais será a mesma. Segundo Bergson, se a nossa existência se resume à coexistência do passado e do presente, o nosso cérebro não pode condensar esta coexistência, pois, dito de maneira bem breve, o passado não se aloja no cérebro. É o mesmo que dizer das lembranças. O problema é que esta questão tem um fundamento em si ontológico e a matéria por si só não toma este problema da coexistência temporal como um todo, amarrado em si mesmo como o são o passado e o presente.

\section{BERGSON: DA SOBREVIVÊNCIA DAS IMAGENS NAS LEMBRANÇAS}

Para que a matéria se torne viva, é preciso do virtual, da capacidade do homem de religar, reconectar e reinserir o mesmo objeto diversas vezes. Quando o presente deixa de ser, o passado já é. Não há presente isoladamente, nem passado isoladamente. Se pensarmos na duração das coisas, elas são eternamente presentes, mas quando associamos a este aspecto a nossa consciência, tudo muda, diferencia-se, o espaço não é mais o mesmo, nem o tempo é mais o mesmo. Bergson (2010, p. 21) no seu célebre livro Matéria e memória: ensaio sobre a relação do corpo com o espírito tece o seguinte raciocínio: "só apreendemos as coisas sob forma de imagens, é em função de imagens, e somente de imagens, que devemos colocar o problema". Bergson denomina de "matéria" um conjunto de imagens e de "percepção da matéria" essas mesmas imagens relacionadas à ação provocada por nosso corpo.

Dissemos anteriormente que o nosso cérebro é um corpo, ou seja, uma matéria, logo, segundo a perspectiva bergsoniana, ele é uma imagem. Enquanto imagem, equivaleria dizer que "o sistema nervoso nada tem de um aparelho que serviria para fabricar ou mesmo preparar representações" (BERGSON, 2010, p. 27). Nesta lógica de apreensão, é o nosso cérebro que faz parte do mundo material, e não o mundo material que faz parte do cérebro. Ou seja, o cérebro faz parte de nossa vida, ele é meramente uma imagem em torno de um turbilhão de 


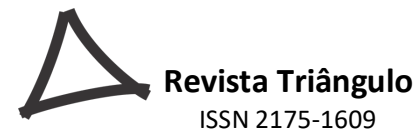

outras imagens dispersas no universo material. Logo, não é a nossa vida inteira que o nosso cérebro condensa, ao contrário, o cérebro é apenas uma pequena parte do universo material. Para que o cérebro contornasse todos os paradigmas de nossa vida era preciso que a representação do universo material inteiro estivesse implicada nos estímulos cerebrais.

Em A energia espiritual, Bergson (2009, p. 73) atesta esta nossa hipótese sobre o cérebro, ele diz: "no meu entender, o cérebro não conserva as representações ou imagens do passado; simplesmente armazena hábitos motores". Ou seja, no trabalho do pensamento em geral, como na operação da memória, o cérebro nos aparece simplesmente como encarregado de imprimir ao corpo os movimentos e as atitudes que representam o que o espírito pensa (BERGSON, 2009, p. 74). Nesta visão particular, é como se o órgão cerebral preparasse a "moldura", não fornecendo a lembrança. E Bergson $(2009$, p. 75$)$ continua: "se a consciência não é uma função do cérebro, pelo menos o cérebro mantém a consciência fixada no mundo em que vivemos; é o órgão da atenção à vida”.

Seguindo este princípio, o nosso cérebro é o responsável por fixar o indivíduo no mundo em que, através dos seus sentidos, o cérebro oferece ao indivíduo o estímulo necessário para lidar e se adaptar aos movimentos anímicos do universo perceptivo. A percepção e a lembrança trabalham juntas no sentido de que o cérebro auxilia na captação e internalização dos aspectos motores da percepção sensorial, enquanto que a lembrança absorve aquele "conteúdo" perceptivo e produz imagens-lembranças. O nosso cérebro, além de suas funções sensoriais, segundo Bergson (2009, p. 75), não faz outra coisa a não ser “imitar a vida mental”. Neste sentido, o corpo é o receptáculo dos estados virtuais. Sendo assim, não há no homem um estado puramente sensório-motor. Para toda percepção há uma lembrança. Só nos lembramos do passado porque o nosso corpo conserva presente a sua marca.

a consciência está incontestavelmente ligada a um cérebro, mas daí não resulta de modo algum que o cérebro desenhe todos os detalhes da consciência, nem que a consciência seja uma função do cérebro. Tudo o que a observação, a experiência e, portanto, a ciência nos permitem afirmar é que existe uma certa relação entre o cérebro e a consciência (BERGSON, 2009, p. 36).

Com esta citação, Bergson quer nos dizer que há muito mais na consciência humana do que meramente no cérebro enquanto correspondente de estímulos motores. Nesta perspectiva, o nosso cérebro não deixa de ser um órgão de representação, mas não representação de imagens coalescentes provindas do estado virtual de algum objeto percepcionado, mas refere-se à representação de movimentos motores e sensoriais. Se eu, por acaso, levanto o braço, antes 


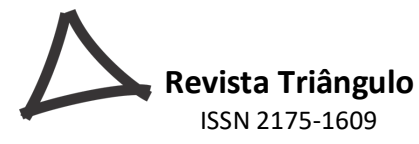

desta execução, foram acionados no cérebro sinapses ou sinais passando a se prolongar em gestos motores. Como nos diz Bergson (2014, p. 82) no livro Aulas de psicologia e de metafísica, "é essa luz interior, esse sentido interior que não tem órgão, que chamamos de consciência. É uma faculdade de observação, mas de observação interior". Seguindo um fundamento ontológico, a consciência, assim como a lembrança, existem por si mesmas e se refletem ordinariamente na emanação do nosso espírito.

Assim como a ilusão do tempo que pensamos que ele passa, que ele se movimenta na extensão do espaço, pensamos também que a consciência passa a ocorrer em nosso cérebro em uma parte decididamente central. Mas, tudo isto é diferente. Ao contrário, o tempo passa em nós, nós é que duramos, nós é que o sentimos. Nesta medida, a duração é algo totalmente relativo ao ser consciente. Logo, o tempo se passa na consciência, ele se torna, digamos, "concreto" na interferência de nossa consciência. Já na matéria, o corpo é objeto de observação da percepção exterior. Quando me refiro a um objeto exterior qualquer, só posso falar da impressão que ele causa em mim, ou seja, de um conjunto de sensações.

Nesta perspectiva, o cérebro, por exemplo, é um objeto exterior a mim. Por que ele é exterior e não interior? Porque interior, na verdade, é a nossa consciência, o nosso espírito, a memória e nossas lembranças. Logo, exterior é todo o objeto que no mundo material se transforma em imagem por intermédio de nossa consciência. Sendo assim, a possível imagem que eu construo com a força do meu pensamento não faz parte do mundo material, ela tem, digamos, um lugar especial em meu espírito. Aqui, estamos nos tratando de um espírito cognoscente que, em seu processo evolutivo, caminha em dois sentidos opostos: seja em direção à espiritualidade, seja em direção à materialidade. Sendo assim, matéria e espírito resumem a nossa vida por inteiro.

A tese em que se lança neste presente estudo é a de que não há, pois, como se conhecer a realidade espiritual por meio meramente da ordem natural do mundo, ou seja, do presente manifesto e ordinário. Se desta forma fosse, teríamos uma visão parcial do que é uma contínua transformação ou mudança constante do movimento anímico do universo como um todo. Segundo Astrid Sayegh (2010), importa partir da interioridade, a qual há de ser a fonte geradora da vida com vitalidade, e não apenas das coisas em sua exterioridade. Esta mesma autora concorda com Bergson ao dizer que "o lugar onde as lembranças vividas se conservam não é um espaço, mas o tempo, a duração" (SAYEGH, 2010, p. 132). E ela continua: "Bergson demonstra de forma positiva em Matéria e Memória, por meio da descrição de casos de afasia, 


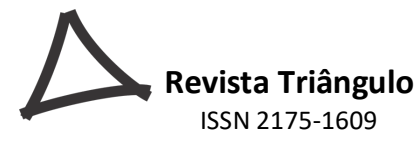

como as lesões cerebrais não destroem as lembranças, mas apenas impedem a sua manifestação" (SAYEGH, 2010, p. 130). Este caso faz crer que se as nossas lembranças se alojassem em nosso cérebro consequentemente elas seriam também danificadas pelo caso da afasia.

No caso da relação entre o cérebro e a memória, segundo Bergson (2010), tudo deve se passar, portanto, como se uma memória independente juntasse imagens ao longo do tempo à medida que elas se produzem, e como se nosso corpo, com aquilo que o cerca, não fosse mais que uma dessas imagens. Partindo desta perspectiva, Bergson quer nos salientar que para todo objeto percebido, há uma sombra ou o seu reflexo, ou seja, o seu modo virtual. Mas, é importante mencionar que este modo virtual de ver as coisas da natureza só é possível graças à manifestação do espírito enquanto uma ordem ontológica. Dito de outra maneira, para cada percepção imediata, há, digamos, uma relação intrínseca equivalente que subjaz à sobrevivência de uma imagem análoga àquela do objeto percebido.

Uma das funções do cérebro nada mais é do que captar, pelo olho, a visão geométrica daquele objeto; já a função de conservá-lo dentro de um paradigma imagético é papel da própria lembrança, ou se quer preferir, de nosso espírito. O cérebro só vai até o ponto em que atinge os movimentos do corpo, ditando a sua ordem, estrutura e funcionamento. Já o papel de conservação se dá espiritualmente na própria sobrevivência da imagem, não encontrando um limite no processo de conservação. A tudo que a gente vê, a gente conserva e é necessariamente sob forma de imagem que este processo se conclui. Ou melhor, não se conclui porque o processo como tal não cessa de acontecer, mas se dilui em um número infinitamente de sensações. Para cada sensação, foi-se engendrado uma percepção e para cada percepção foi-se constituída uma imagem.

Se, através de um exercício espiritual, nós podemos ver o nosso cérebro fora de nós mesmos, então, desta forma, o cérebro, seguindo a hipótese de Bergson, nada mais vai ser do que uma imagem em relação a outras tantas imagens que a força criadora do nosso espírito cria. Sendo assim, a construção do real se dá no desenvolvimento incessante de imagens uma vez que, muitas destas imagens, no "fluir" de nossa consciência, não se cristalizam a ponto de nós lembrá-las integralmente. Nós não lembramos de uma imagem de forma completa, mas sim de estilhaços dela, assim como de um espelho que se quebra após involuntariamente o indivíduo enxergar a sua imagem especular refletida. Assim como o indivíduo vê a sua imagem no espelho, tendo, na mesma medida espacial, a sua semelhança, o objeto em si percebido contém 


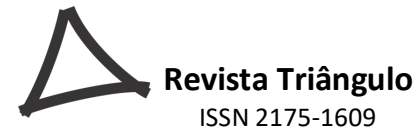

a sua própria imagem, a sua sombra, o seu reflexo. É como se um mesmo objeto contivesse duas grandezas existenciais distintas, a saber, o atual e o virtual.

Porém, é importante dizer que para que o objeto tome o seu lugar virtualmente, é preciso a presença da consciência do indivíduo para que este processo se consolide. Segundo Izilda Johanson (2014, p. 123), “o conhecimento, em Bergson, se identifica com a experiência criadora e pressupõe, mais do que o envolvimento do indivíduo com seu objeto, a constituição conjunta do próprio indivíduo e seu objeto". A construção do real e, mais do que isto, do virtual se dá na invenção, na potência ou evolução criadora que, segundo Bergson, consiste em construir novas formas de percepção ou de intelecção contra a homogeneidade do universo material. O fato fundamental na ordem do princípio espiritual é o de durar, ou seja, a sua propriedade mnemônica. Ou seja, um objeto qualquer, lançado na extensão do espaço, não dura por ele mesmo, mas chega a se tornar "eterno" com a propriedade mnemônica própria do indivíduo. Esta propriedade é a da conservação.

O homem inventa para durar, para passar a existir além do mundo material. Se fôssemos partir tão somente do efeito cristalizado encarnado em um objeto, iríamos viver apenas o hábito da repetição, decompondo e compondo o mesmo. Em contrapartida, "ao partirmos do impulso criador que há em nós, tudo se clara, tudo se torna luminoso de modo a perceber os caminhos da vida em evolução" (JOHANSON, 2014, p. 208). Segundo Bergson (2009), é uma ilusão pensar que a formação da lembrança é posterior à da percepção, ao contrário, é sua contemporânea. “À medida que a percepção se cria, sua lembrança vai se perfilando a seu lado, como a sombra ao lado do corpo" (BERGSON, 2009, 128-129). Ao mesmo tempo em que se percebe, se cria, inventa. E esta invenção se dá na seleção da constelação de imagens que vão se insinuando à nossa frente, no "corpo" de nossa consciência interior.

Neste sentido, o objeto percebido existe tanto exteriormente, no espaço circundante, como interiormente, como sombra em nosso espírito. Fora do espírito, tal objeto é eternamente presente. No interior do espírito, tal objeto é provisoriamente virtual. "Provisoriamente" porque nada na constelação de nossas lembranças é eterno. Tudo muda, tudo diferencia-se. A não ser a "lembrança pura" que, em termos bergsonianos, é a ontologia pura e a origem de nossas representações. 


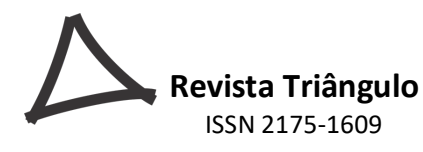

\section{CONCLUSÃO}

Diante daquilo que foi exposto aqui, tentamos, na medida do possível, tecer algumas considerações em torno do problema: onde as nossas lembranças se conservam? Fundamentando-se, principalmente, na filosofia da existência de Bergson em suas três obras principais, a saber, Matéria e Memória, A Energia Espiritual e Aulas de Psicologia e de Metafísica, recuperamos alguns pontos conclusivos em torno daquele problema filosófico. As nossas discussões levam a crer que não existe aparentemente um local em específico que "abrigue" as nossas lembranças. Segundo Bergson, as lembranças existem por si mesmas, o passado está em si, ou melhor, as lembranças estão "na" duração. Logo, partindo-se desta perspectiva bergsoniana, é uma ilusão crer na suposição dos neurocientistas de que as nossas recordações se conservam em alguma parte específica de nosso cérebro.

Chegamos à conclusão de que o cérebro é, na verdade, uma imagem dentro de tantas outras imagens que a nossa consciência, a partir de seu elemento ontológico, cria. Sendo assim, a conservação de nossas lembranças segue um rigoroso itinerário de construção incessante de imagens que se aglomeram entre si, sendo unicamente a subjetividade humana a responsável por detectar qual, dentre as imagens, é a mais semelhante com o objeto percebido. Para finalizar, deixo a afirmação de Gilles Deleuze (2012, p. 113) quanto à nossa discussão aqui proposta: "dentre todas as teses de Bergson, talvez esta seja a mais profunda e a menos compreendida, a tese segundo a qual o passado sobrevive em si”.

\section{REFERÊNCIAS}

BERGSON, H. A energia espiritual. Tradução de Rosemary Costhek Abílio. São Paulo: Martins Fontes, 2009.

BERGSON, H. Matéria e memória: ensaio sobre a relação do corpo com o espírito. Tradução de Paulo Neves. São Paulo: Martins Fontes, 2010.

BERGSON, H. Aulas de psicologia e de metafísica. Tradução de Rosemary Costhek Abílio. São Paulo: Martins Fontes, 2014. 
DELEUZE, G. Bergsonismo. Tradução de Luiz Orlandi. São Paulo: Editora 34, 2012.

JOHANSON, I. Bergson: pensamento e invenção. São Paulo: Fap-Unifesp, 2014.

SAYEGH, A. Bergson - A consciência criadora: metafísica da ciência. São Paulo: Humanitas, 2010 . 